\title{
Illuminating five possible dimensions of self-care during the COVID-19 pandemic
}

\section{Original Research}

Narelle Lemon ${ }^{1}$

${ }^{1}$ Department of Education, School of Arts, Social Sciences and Humanities, Swinburne University of Technology, Melbourne, Australia

Corresponding author: N. Lemon (nlemon@swin.edu.au)

\section{ABSTRACT}

Background: Self-care is about taking care of yourself. It is a proactive action involving steps to develop, protect, maintain and improve health, wellbeing or wellness. Self-care can be seen as a repertoire of practices - different things you can do that help you care for you, no matter how small. It is an act of treating yourself like you would a close friend. The importance of valuing self-care has not changed in light of the COVID-19 pandemic, in fact, more awareness and appreciation for what one can do to empower yourself may indeed be valued more. Methods: In this paper, I draw on data from 53 participants aged over 18 years who responded to an online qualitative questionnaire between the months of May to June in 2020. Poetry derived from all the participants has been generated to both represent their voice and to provide a provocation that ignites our hearts and mind to consider what is good in life. Results: To further conceptualise self-care, I propose and present five possible dimensions of self-care (mindfulness, self-compassion, habits, time and agency). Aspects within these dimensions are described juxtaposed with poetic representation that illuminates practices and mindsets engaged with during the COVID-19 pandemic. Conclusions: When thinking about self-care across five possible dimensions, the framework I propose becomes useful for capturing a holistic and authentic view of both proactive actions and how a variety of practices can be engaged with. Empowerment is possible in partnership with self-compassion and awareness, where a self-kindness supports proactive decisions to be made on a daily basis that support wellbeing. Central is that no matter one's experiences with suffering during a pandemic, gratitude and awareness for oneself is possible.

\section{KEYWORDS}

Empowerment, Gratitude, Poetic representation, Self-care, Self-compassion,

\section{BACKGROUND}

When we think about self-care, it is not uncommon for there to be reactions that reveal a rhetoric of "as if I have time", "that is selfish", or "I just don't know where to start". Add a pandemic and pressures around what self-care is, what it can look like for one, and what it looks like in practice rise. But for some, COVID-19 has provided an opportunity to be reflective and reconsider, rethink, reframe and redirect how one cares for oneself. The pandemic has created an opportunity for a pause and a selfawareness to emerge where empowerment is possible in partnership with self-compassion that ignites a humanity and self-kindness. It is possible to be present non-judgmentally although there is suffering; acknowledging everyone is doing the best they can. In this paper, I draw on data that was collected from participants over 18 years of age, from across the world who live their lives embraced in various disciplines, jobs, life stages and contexts. In an online qualitative questionnaire, participants were asked to reflect upon both self-care and COVID-19 from a flourishing perspective, or what is good in life. One of the aims was to significantly rebut and shift the louder rhetoric's, and thus provide a provocation, of self-care was not, and is not, possible during a pandemic. 
In this paper I draw on a conceptual model of selfcare that I have developed informed by positive psychology literature and research (see for example Lemon, 2021; Lemon \& McDonough, 2020) that refers to five possible dimensions of self-care (mindfulness, self-compassion, habits, time and agency) then locate what this looks like in practice based on participants self-identified enactment of self-care. I work with the data in a different way, sharing poetry generated from the participants data in response to the question: What are 3 good things that you have noticed in your protection, maintenance and proactive actions for self-care at this time? Görlich (2016) argues that through poetic inquiry it is possible to create "evocative analyses that are able to broaden understandings, create dialogue and increase understanding of the polyvocality of experience" (p. 525). It is poetic representation that in this paper enables us to reflect upon what self-care can be, and what might be possible, especially in the time of a pandemic. The poetry is presented as a way to seek to broaden the conversation about self-care during COVID-19 by considering the role that positive psychology may have, specifically the adoption of seeing what is good in life and considering how one may still flourish at a time when there are strong negative emotions and for some with experiences of psychological distress. In this way, poetic representation invites you as a reader to engage both emotionally and cognitively with the concepts (Januchowski-Hartley et al., 2018), and I invite you to enter a dialogue about what might be possible when we think about our self-care.

\section{Our love hate relationship with self-care}

Self-care is a proactive action that facilitates taking care of yourself. It involves steps to develop, protect, maintain and improve health, wellbeing or wellness. It is about meeting yourself each day, learning who you really are and continuing to be present with your needs to help you be the best version of yourself today. It's a process of self-discovery, not perfectionism or comparing yourself to others (Lemon, 2021; Lemon \& McDonough, 2021). Self-care is, however, complex as the practice involves factors that support change or actions that require modification. Limitations also need to be acknowledged here in the individual's ability and capacity to take proactive action (Gbhardt Taylor \& Renpenning, 2011). Additionally, although selfcare

IHTP, 1(2), 161-175, 2021 CC BY-NC-ND 4.0 locates the self in one's wellbeing, thus placing the individual at the centre of proactive action (AdkinsJackson et al., 2019), it is not an entirely individual act. Self-care is both an individual and collective action with reliance on relationships with others (Duggan et al., 2018; Eller et al., 2018; Gbhardt Taylor \& Renpenning, 2011; Narasimhan \& Kapila, 2019). Family, dependants, community, workplaces, and/or culture plus systems such as healthcare available and their policies, processes and structures are pivotal to self-care.

Self-care ranges from a set of activities to a set of capacities (Narasimhan \& Kapila, 2019). However, defining self-care is a contested area (Godfrey et al., 2011; Matarese et al., 2018). Christina Godfrey and colleagues in their analysis of practice, policy and industry perspectives in relation to self-care found 139 different definitions of self-care with little consensus on finding an agreeable definition in healthcare literature. However, we can identify that definitions usually align to two perspectives: 1) focus on improving the capacity of individuals to care for oneself, and 2) focus on how self-care relates to the health system (Narasimhan et al., 2019). Revealed in the research is that self-care is positioned within cultural and social norms, revealing tensions between access and responsibility, and the perceived value (Duggan et al., 2018; Eller et al., 2018). There is much debate on the place of self-care as a part of everyday. Tensions exist in regard to self-care being an individual responsibility verses being something engaged in when there is a problem that requires professional healthcare services and thus a system responsibility. A significant gap is seeing self-care as an action that can empower one individually and collectively in the everyday.

Self-care for some individuals still feels selfish, and it is something they find hard - they don't have time, find it difficult, compare individual practices to others, and find that they discard good wellbeing decisions even though they know it will be helpful when they are feeling under pressure or stressed (Duggan et al., 2018; Eller et al., 2018; Godfrey et al., 2011; Kissack, 2018). During the pandemic this has been prevalent (Fiebig et al., 2020; Horesh \& Brown, 2020; Valizadeh-Haghi et al., 2021; Waters et al., 2021), with a significant focus on research that highlights the ways in which people are wounded and weakened. Furthermore, much research, media and

ISSN 2563-9269 
popular culture has not been able to contribute beyond just considering the pandemic, ignoring or gleaning over how wellbeing and self-care can be bolstered (Waters et al., 2021). Even before COVID-19 became a reality, there is evidence that there is a reliance on professional healthcare services to provide solutions (Riegel et al., 2019). We can see this with the World Health Organisations (WHO) definition of self-care noting action is "the ability of individuals, families and communities to promote health, prevent disease, maintain health, and to cope with illness and disability with or without the support of a health-care provider" (World Health Organisation, 2013, p. 15). What we notice about this definition is that self-care is focused on the prevention of disease as the primary aim. In this interpretation of self-care, chronic illness and solutions for administration of medications for the management of mental and physical health ailments dominate (Boyde et al., 2018; Parulekar \& Mekoth, 2017; Riegel et al., 2012, 2018; Vanwesemael et al., 2018). Self-care is more than this, it is about the everyday acts we undertake to be proactive. This uncovers the need to look at self-care education and a rethinking of interventions, and indeed the place of self-care, that empower individuals in their self-care practices while raising self-awareness and also building confidence and capacity (Adkins-Jackson et al., 2019; Duggan et al., 2018; McGarrigle \& Walsh, 2011).

Essential for the enactment of self-care is daily practice that individuals initiate and perform on their own behalf that support them in maintaining life and wellbeing (Denyes et al., 2001; Gbhardt Taylor \& Renpenning, 2011). This requires balance between self-awareness and self-regulation (Baker, 2004), with an agency and that supports addressing imbalance to sustain equilibrium (Adkins-Jackson et al., 2019). Thus, it is suggested that the act of self-care is underpinned by awareness and reflection to support personal growth (Cook-Cottone \& Guyker, 2018). Selfcare is, therefore, comprised of some actions within an individual's control to manage wellbeing (Narasimhan \& Kapila, 2019).

While it is reported that self-care interventions increase choice (Narasimhan \& Kapila, 2019), there is however, a gap in promoting self-care as a proactive action to thrive (Narasimhan et al., 2019). This is noted in how challenges to self-care are reported.
Observed is that choice and empowerment are missing especially in how self-care can be applied consistently and through the everyday in order to support wellbeing with challenges often positioned at blaming others or systems, or the act being difficult. The growing interest in the concept of self-care and that making time for self each day in order to process stressors and worries, and to focus on key life goals that align to meaning and purpose is required (Magyar-Moe, 2014). This is a significant area that this study addressed, specifically looking at self-identified self-care that individuals enact daily to assist them during a dynamic and changing time such as COVID19. The importance of valuing self-care has not changed in light of the COVID-19 pandemic, but the ways in which we engage with that value may need to have changed. Specifically, this study aimed to understand how individuals self-identify that they flourish with their self-care during COVID-19. The overarching research question was: What does selfcare look like during a time of dynamic change such as COVID-19? This is informed by positive psychology, a relatively new field of psychology, that focuses research on positive variables that enhance wellbeing, including notions of flourishing (Lomas et al., 2014). Flourishing is a state where one can be their authentic self. To flourish is to find fulfillment in our lives, accomplishing meaningful and worthwhile tasks, and connecting with others at a deeper levelin essence, living the 'good life' (Seligman, 2011). Flourishing is a state where people experience positive emotions, positive psychological functioning and positive social functioning, most of the time, living within an optimal range of human functioning (Lomas et al., 2014).

\section{METHOD}

This paper draws on questionnaire data collected between the months of May to June in 2020. This was a time when lockdowns, restrictions and boarder closures were occurring globally. Participants were recruited via a modified snowball method (Parker et al., 2019) including professional social media accounts (Instagram, Twitter, Facebook and blog). Others who saw the invitation to participate in the online questionnaire were also encouraged to share to a wider audience who may be interested in participating. 
While the data collection questionnaire was accessed 59 times, there were 53 participants. $88 \%$ of the participants identified as female $(n=47)$, and $7.5 \%$ identified as male $(n=4)$, with the remainder identifying as prefer not to say. $62 \%$ participants were between the ages of 31- 50 years $(31-40=14 ; 41-50=$ 19). $24 \%$ were aged between $51-60$ years $(n=13)$, $5.6 \%$ were aged $25-30$ or $61-70$ respectively $(n=3$ each), and $1.9 \%$ were aged between 18-21 years $(n=1) .62 .22 \%(n=33)$ were from Australia, with $7.5 \%$ $(n=4)$ from UK, 5.66\% respectively from the each of Malaysia, Canada and USA ( $n=3$ from each country), 3.8\% from New Zealand and Germany respectively ( $n=2$ from each country), and 1 person from Scotland, Switzerland and Ireland. Participants identified themselves from a variety of vocations including being a student, teaching, nursing, being selfemployed, social work communications, health, and evaluation. The demographic data shared provides an overview of participants, but it not relevant to the analysis of data in regard to how it is used in this paper, rather presented as part of the trustworthiness criteria (unpacked further in this paper).

\section{Data Collection: Questionnaire}

Data was collected via a Qualtrics questionnaire with 16 items. The questionnaire was developed by the author of this paper based on literature from the field of positive psychology and the notion that selfcare requires addressing diverse areas of wellbeing (Seligman, 2011). Considered but not limited to were wellbeing frameworks that could be used to scaffold this, for example PERMAH (positive emotion, engagement, relationships, meaning, accomplishment, health) as one such framework (see for example McQuaid and Kern's (2017) development of this framework with the addition of $\mathrm{H}$ from Martin Seligman's (2011) original PERMA framework) or Five Ways of Being (connect, be active, take notice, give, keep learning) (Marks et al., 2008). Crucial in the design was the underpinning assumption that selfcare and wellbeing is developmental, and a variety of strategies or practices can allow individuals to build on their talents and what energizes them in order to support their wellbeing (Louis \& Lopez, 2014). Five questions were to elicit demographic information, while 11 content questions invited participants to share their experiences of how they have approached self-care during the pandemic from the perspective of flourishing. Questions prompted participants to consider how ideas of self-care had changed during COVID-19 (awareness); how one would describe their attitude to self-care right now (engagement); how one treats themselves as a friend during this time (self-compassion); three good things one has noticed in themselves in their protection, maintenance and proactive actions for self-care (gratitude/positive emotions); new habits (meaning / accomplishment); the place of online to support movement (health), connections with others (relationships) and emotions (positive emotions); an expression of appreciation to self (appreciation / positive emotions); and a strategy that could inspire others during the pandemic (awareness / relationships / positive emotions).

One question from the data produced is shared in this paper: What are 3 good things that you have noticed in your protection, maintenance and proactive actions for self-care at this time? Gratitude is a fundamental element of human flourishing (Henning et al., 2017). As a positive emotion, gratitude is an essential part of one's orienting system that is of significant benefit during the time of a pandemic (Waters et al., 2021). In a study of 511 adults who were surveyed online during March to May 2020, Watkins et al (2021) reported that they were quite grateful, even in the midst of the pandemic. Over $56 \%$ of respondents reported being very grateful, which was $17 \%$ greater than any other positive emotion (happy, hopeful, relieved, joyful). Additionally, it was noted that three significant gratitude-related areas of perceived changes in the self were observed during this period: 'Are more grateful for the positive aspects of life'; 'Have a greater understanding each day that we are alive'; and 'Have a better sense of what is important to me.' Participants increased their gratefulness the more they observed it, reporting the more grateful they were, the more they reported these positive selfchanges. As gratitude can be cultivated through simple practices such as journaling or reflections such as noting 3 blessings (small acts we can often forget to appreciate in our day) or 3 gratitude's (Fishman, 2020; Lyubomirsky, 2010; Watkins, 2014), what is important in thinking about gratitude and appreciation during a pandemic is that we can express gratitude toward ourself and others in different ways (Fishman, 2020) and these small acts have a positive impact on our wellbeing during a time of crisis and uncertainty. 


\section{Ethics of care for participants}

During the dynamic times of COVID-19, individuals and collectives have different experiences. Important in designing this research was the work of Jandrić (2020) who wrote in March 2020 that "academics have a unique opportunity, and a moral duty, to immediately start conducting in-depth studies of current events" (p. 234). This research aimed to highlight the positive experiences and gain insights into what this may be like for those who identify in this way. It is acknowledged though, that this perspective is one, and for some the idea of flourishing or feeling empowered is not one they are experiencing in this unprecedented time with trauma, anxiety, stress, and suffering present. Ethically this was acknowledged during data collection, and as such, the invitation and questionnaire framed this at the beginning of the information sheet from a space of mutual respect and compassion. Each of the 11 content questions were voluntary, so participants could elect to provide a response or not. Numbers of questionnaire responses therefore varied across each question. The decision to make each of the questions 'opt-in' was associated with the desire to respect each participant's right to choose which aspect of their experiences that they wished to comment on. This came from a space of awareness, mutual respect and compassion in not wanting to ask too much of participants during the pandemic and giving them flexibility, over which questions they could respond to was part of our response to this consideration. Ethical care for participants was a part of the formal institutional ethics approval process from the university Human Research Ethics Committee (Swinburne University of Technology reference number 20202963-4352).

\section{Thematic analysis}

Manual coding of the qualitative data was undertaken by the researcher, and cross checked by a research assistant. The process began by inductively coding for key concepts or phrasing that aligned to five intersecting dimensions of proactive self-care: mindfulness, self-compassion, habits, agency, and time (Figure 1).

I followed a thematic approach; searching for patterns and relationships to "find explanations for what is observed" (Boeije 2010, p. 76) through segmenting and reassembling. Trustworthiness of the qualitative inquiry comes from the revealing of the content analysis process. The depth of this process is outlined in the following section where the formation of the poems is outlined. Furthermore, the criterion of credibility (the research design and participant demographics are described accurately, with awareness of researcher bias); dependability (stability of data over time and under different conditions noting how the data was collected and the context); conformability (the potential for comparisons between two or more independent people about the data's accuracy, relevance, or meaning); transferability (the extent the reader can consider the findings can/may be transferred to other settings or groups); and authenticity (showing a range of realities) have been embraced throughout this research (Lincoln \& Guba, 1985; Elo et al., 2014; Guba \& Lincoln, 1994; Polit \& Beck, 2012).

The findings are presented under each of these dimensions, represented in poetic format promoting a way for the reader to engage with the lived experiences of the participants in a way that ignites a mind, body and emotional response (Richardson, 1997).

\section{Poetic representation of the data}

Working with data and presenting it through poetry can be a risk (Lemon, 2021). However, working this way ignites a response from the reader - it creates a dialogue, broadens understanding, presents a different perspective, and invites one to reflect and be present with moments of celebrations, suffering, worries, and learning (Görlich, 2016; Lemon, 2021; Lemon \& McDonough, 2021; McDonough, 2018). Like any form of qualitative data analysis, however, the process of constructing poetic representations involves "sifting through data" to identify words, phrases and extracts that "synthesize meaning" (Prendergast, 2009, p. xxiii). Immersion with the data and analysis according to identified dimensions of self-care was drawn upon (in this case informed by the framework of self-care being considered in this paper). All data was included with the exact phrasing as the participant had written in response to the questionnaire question. Patterns were identified within a theme to find replications and or sub themes that helped shape the poem. The participant voices 
were moved around to form a poem with stanzas. Every participant is represented in each poem.

\section{RESULTS AND DISCUSSION}

\section{Self-care practices during a pandemic}

\section{Mindfulness.}

I'm finding relaxation exercises to be so much more appealing

simple things can be very powerful

more affectionate and attentive

engagement with my pets

having plans on my calendar to

give structure to my days

Taking long and different walks

around my urban neighbourhood

I've noticed so many different things that

never knew were there

Taking long bike rides into and along the nearby linear parkland

river

woodland and

fields

I realise how much I

enjoy being amongst nature

Take note of smaller things is good

patience has increased

ability to put thoughts and actions into perspective has increased

empathetic responses to others have increased.

Slowing down mentally

exercise

more reading

practising creativity

journaling regularly

keeps things from getting overwhelming

keeps me in touch with my emotions

I often learn things that I didn't realize I

was feeling

I value connection with others even more
I've realised that social acts are more important to my self-care than I thought

the strength of some of my relationships

talking with other people going through the same experiences

I'm getting to spend time with my teenagers in a better way

my boyfriend and I communicate better now after spending so much time together

Been able to look after my family including elderly parents

reaching out to friends for connection has also been huge

having (virtual) events or plans to look forward to keeping me anchored and energized

There are many different ways to connect with mindfulness, just as there are many different reasons for one to connect or not with mindfulness (Roche, 2020). Mindfulness in relation to self-care is about being present in this moment in time, and nonjudgmentally tuning into what is needed right now. The listening to one's needs is crucial. What this poem reveals are that for the participants of this study mindfulness is an entire mode of knowing. It is about awareness for self and others. That even during a pandemic there are practices and strategies to support, maintain and protect self-care that enhance - connecting with relaxation techniques, enjoying nature, journaling or engaging in creative pursuits, savouring time with pets, connecting to relationships with own children, parents, friends, and partners. All these acts required intention (knowing where the attention is, and prioritising where the attention needs to be), attention (becoming fully aware of moment-to-moment internal experience), and the cultivation of an attitude (the approach via acceptance, kindness and curiosity) (Shapiro et al., 2006). It is through cultivating mindfulness, that compassion, kindness, gratitude, awareness, openness and curiosity can be fostered alongside a quietening of the mind, improved focus, selfregulation and self-awareness (Aviles \& Dent, 2015; Shapiro et al., 2006; Shapiro \& Carlson, 2017). 


\section{Self-compassion.}

My compassion for myself and the world I think also the realisation that nothing bad will happen externally if I take care of myself I have recognised the need for self-care

Being less hard on myself asking myself questions - keeps me accountable to me

I am pausing more in the evenings and on the weekends

I'm more patient with myself and others less self-critical and happier recognizing that I need to stop when my body and mind tell me to

I sleep much better

I am a better mum

I listen to my heart much more

I am happier

I do not feel guilty for taking care of myself

I am more productive in my workplace

I let myself sleep

I let myself cry

I'm eating better

Gentle flow,

if I feel like a walk, or bath or whatever... I just do it really engage appreciate whatever the self-care is... savouring every moment feeling very grateful for what is good

Self-compassion involves being kind and understanding toward oneself rather than being harshly self-critical, even in instances of uncertainty, unknown, pain, failure or worry (Neff, 2003). Selfcompassion is a journey. On this journey the unexpected can emerge for us, and this can be activating. We close our hearts in this moment. That is a coping mechanism. During COVID-19 for many of us we have been confronted with the need to comfort ourselves, to sooth our self. There has been a need to be present, enact a mindful awareness to allow for self-compassion to spring from the heart (Neff \& Germer, 2018). Kristen Neff's work in self-compassion places mindful awareness, kindness to self, and common humanity as three central pillars. These are crucial for self-care. This poem allows us to connect to the lived experiences of others and to engage with an awareness of what ones needs and embraces when they have the chance to treat oneself like a friend. Mindfulness is vital in self-compassion as a means to anchor awareness in the present moment (Neff \& McGehee, 2010). Self-kindness has us being encouraging, supportive, unconditionally accepting. This is our soothing action to ourselves. And we are able to remind ourselves that everybody is complex, everybody is suffering and learning from their lived experiences. The common humanity pillar is a reminder that we all suffer, pain is a part of the shared human experience, and that every moment of suffering can be transformed into a moment of connection, with self and with others.

Time.

Flexibility

blocked out time

scheduled sessions

doing more things, I enjoy

rather than the things I 'should' be doing

I have blocked out time in the morning so, I can start the day more slowly gives me a chance to get the kids ready for school then have breakfast while planning my day

I have become better at blocking out time in my online work calendar

so, I can focus on getting work done

I scheduled 'afternoon tea' sessions with my team twice a week via Zoom and we laugh together

I continue my self-care of magazines and a bubble bath
ISSN 2563-9269 
I'm exercising more than I ever have increased productivity in both work and the 'to do' list around the house

The biggest thing is that I can self-care in super short moments

while an hour painting isn't possible a quick "deep breath" or a slightly longer hot shower makes life survivable!

Self-care requires time. However, time is a variable that utilises micro-moments right through to lengthy practices or strategies. We can engage in daily activities, once a week, once a month, once a year for example. What is crucial is that a variety of strategies and practices are engaged with intentionally across a variety of time periods. There is value in a self-care strategy that empowers that may take a few minutes, such as a short breathing practice, just as much as a practice that takes slightly longer, such as a shower, and just as much as something that takes longer such as sleep. It is the proactive action that empowers and energises one that is key. Self-care thus does require intentional awareness of time, and for some during COVID-19 there has been a realisation of blocking this time out or dedicating parts of a day to undertake a specific self-care action is required, and beneficial.

Habits.

Setting limits and boundaries between work and home

my ability to say no more often getting dressed

I know that sounds silly

but it makes me feel better

I've proactively changed

the time of daily outside walk to

lunchtime when it's warmer

rather than early morning

(that I used to do before driving

to work)

this has enabled maintenance of

this practice
I've purposely not increased

wine intake at night

(despite strong temptation)

so, this protects me from creating a bad habit

I was definitely more assertive about housework after old habits became bad habits the new order is helping

Sleep routine

reading in the evenings before bed

continuing to eat healthy

I enjoy cooking more than I thought I view my family menu plans for health

first and not convenience + health

time for making healthy meals

Get outside when possible

I won't let anything come between me and outside/exercise time

if it gets delayed it gets rescheduled that day

Habits are about making small changes (Duhigg, 2012; Lea et al., 2015; Riegel et al., 2019). These small changes accumulate over time to make a big difference. Often, we can underestimate the small changes, the small tweaks we make to our thinking or behaviour thinking they don't make a difference. But in fact, it is the small, tiny little tweaks we make, that add up and contribute to improvements in ourselves. Taking responsibility for our wellness requires us to tune into our habits and cultivate an awareness around both what we need to do for our self in relation to self-care and what this can look like (The Global Happiness Council, 2018). What this poem reveals are that during COVID-19 core self-care strategies were enacted that returned us to the repositioning of health - sleep, healthy food decisions, exercise and sleep - as featured habits that were essential.

\footnotetext{
Agency.

Protection for self-care

being forthright about my reasons for doing
} 
something

giving realistic reasons to explain why I am doing this

I decided on a few channels to get my news from ... and only look at those.

This prevents eternal scrolling and reading

That I am actively stopping myself from going through social media instead using that time to do something productive that I will enjoy more

I have cut out some of the negative/overly political commentary on my social feeds you can't hide from it,

but you don't have to consume it all the time

Maintenance for self-care doing activities that do hold value for me give me pride in completing

I get dressed every day in professional clothing, including doing my hair, putting on some lipstick and concealer and accessories.

This maintains my usual habits and helps me 'change' mindsets

from bed to work to home time.

I try to keep myself engaged in fun things I like, puzzles

and books and PhD

Proactive actions for self-care:

For me personally

these tend to be the first habits to go out the window

during a stressful time

and the hardest ones to build back in, so, having them all working smoothly is a huge goal when I get stressed!

It can help me break cycles of anxiety or isolation much faster

Taking care of my physical health has also been incredibly important for my self- care right now

Whether it's getting enough sleep

hint: at least as much as usual or more drinking enough water eating things which are green, and moving/exercising most days have helped me feel better

Being able to go to shop and get the items I need to complete the activity

I've kept up with my personal trainer via video call I work out with my limited equipment at home working out helps my immune system and helps me avoid back pain, so it's also protective!

Trusting my gut feelings

of anxiety as being a strength that protects me from harm and keeps me going

feeling able to say no or bow out of unnecessary requests on my time

The balance has returned in the new normal I like having the choice of when with whom and how engaged I am I've been able to worry less about what I

'should' be doing

I'm more in control

in every aspect of my life right now

Staying home means staying safe

From a positive psychology lens, agency, empowerment and choice with self-care come from the opportunity to build wellbeing resources from what works and is good in life. It is about connecting with what energises you, enables you to utilise your strengths, and supports you to make decisions that promotes and recognises who you are (McQuaid \&
ISSN 2563-9269 
Kern, 2017; Seligman, 2011; Lemon, 2021). Self-care requires an agency and empowerment of choice that broadens and builds resources for us (Fredrickson, 2001; Garland et al., 2015) it is more than just focusing on preventing disease, caring careers or what is wrong (Eller et al., 2018). Self-care is about paying attention to what you really need. It is about being present, assessing, observing and being curious about one's needs with a compassion that is soothing and supportive. As we inquire with ourselves, we are able to put into place practices and habits to support our needs, that lead to maintaining, healthy boundaries. Self-care is a path to empowerment. Empowerment is proactive and allows for considerations of how one can be autonomous within systems of support. As we develop knowledge, we gain confidence (Ludman et al., 2013). With confidence we are able to become more motivated and gain self-determination abilities. This might include being able to communicate our needs, seeking professional health more proactively, and being able to express concerns or preferences (Chen et al., 2014). During COVID-19 this poem reminds us that our agency is varied, it is beyond a pandemic as well, however it is the universal pause and interruption to how we have lived our lives that has provided for some an ability to reclaim our sense of who we are. Asking questions of self and of others with a curiosity supports wellbeing (Chen et al., 2016; Kashdan et al., 2011), it empowers us.

\section{CONCLUSION}

Through poetry I invite you to engage with these provocations as a beginning point to position self-care as possible. While we can impact others by expressing gratitude directly, we can greatly enhance our own wellbeing by articulating gratitude in written or spoken form, even to ourselves, which allows us to focus in the moment on what we appreciate and brings us joy, happiness, or satisfaction. The expression of gratitude towards self in regard to the act of self-care during COVID-19 by the participants of this study informed the poetry. Revealed is that selfcare is varied but can be empowering, even during an uncertainty, the unknown, and significant changes. Self-care requires attention for all of us. COVID-19 has reminded us all of the place of and value in self-care. What is evident in these poems that represent lived experiences of what self-care can look like during a pandemic from the lens of participants gratitude and appreciations, is that self-care is possible when under pressure and while experiencing dynamic changes and uncertainty.

Reconfirmed is that not one strategy works for everyone and that multiple intentional activities across variety of different wellbeing areas are essential, and indeed possible. Although routines and rituals all changed for everyone, COVID-19 bought to the forefront capacity for awareness, specifically tuning into needs for right now with a curiosity that supports novelty, challenge, and uncertainty. During a pandemic awareness for positioning self-care as worthy of our attention is illuminated. When thinking about self-care across five possible dimensions, this new framework proposed becomes useful for capturing a holistic and authentic view of both proactive actions and the variety of practices that can be engaged. Empowerment is possible in partnership with self-compassion and awareness, where a selfkindness supports proactive decisions to be made on a daily basis that supports wellbeing and shifts viewing self-care from a deficit way of thinking and being that blames others, systems, or the act being difficult. Central is that no matter one's situation, difficulty and suffering during a pandemic, self-care is possible and gratitude and appreciation for oneself is achievable.

\section{ACKNOWLEDGEMENTS}

This research was undertaken in Narrm (Melbourne) after a hard lockdown over June-November 2020 with this paper written during a short five day "circuit breaker lockdown" in February 2021. Narrm occupies the unceded Lands of the Wurundjeri and Boon Wurrung peoples of the Kulin Nations. I give thanks and pay my respects to the traditional custodians, and elders past and present of these Lands, Waters and Skies. We undertake to respect and uphold the responsibilities of being On Country.

\section{REFERENCES}

Adkins-Jackson, P. B., Turner-Musa, J., \& Chester, C. (2019). The Path to Better Health for Black Women: Predicting Self-Care and Exploring Its Mediating Effects on Stress and Health. The Journal of Health Care Organization, Provision and Financing, 56, 1-8. 
International Health Trends and Perspectives

https://doi.org/10.1177/004695801987096 8

Aviles, P. R., \& Dent, E. B. (2015). The Role of Mindfulness in Leading Organizational Transformation: A Systematic Review. The Journal of Applied Management and Entrepreneurship, 20(3), 31-55. https://doi.org/10.9774/gleaf.3709.2015.ju. 00005

Baker, E. K. (2004). Caring for ourselves: A therapist's guide to personal and professional wellbeing. American Psychological Association. https://doi.org/10.1037/10482-001

Boeije, H. (2010). Analysis in Qualitative Research. Sage Publications Ltd.

Boyde, M., Peters, R., New, N., Hwang, R., Ha, T., \& Korczyk, D. (2018). Self-care educational intervention to reduce hospitalisations in heart failure: A randomised controlled trial. European Journal of Cardiovascular Nursing, 17(2), 178-185. https://doi.org/10.1177/147451511772774 0

Chen, J., Mortensen, K., \& Bloodworth, R. (2014). Exploring Contextual Factors and Patient Activation. Health Education \& Behavior, 41(6), 614-624. https://doi.org/10.1177/109019811453178 1

Chen, J., Mullins, C. D., Novak, P., \& Thomas, S. B. (2016). Personalized Strategies to Activate and Empower Patients in Health Care and Reduce Health Disparities. Health Education and Behavior, 43(1), 25-34. https://doi.org/10.1177/109019811557941 5

Cook-Cottone, C., \& Guyker, W. M. (2018). The Development and Validation of the Mindful Self-Care Scale (MSCS): an Assessment of Practices that Support Positive Embodiment. Mindfulness, 9(1), 161-175. https://doi.org/10.1007/s12671-017-0759-1

Denyes, M. J., Orem, D. E., \& Bekel, G. (2001). SelfCare: A Foundational Science. Nursing Science Quarterly, 14(1), 48-54. https://doi.org/10.1177/089431840101400 113

Duggan, M., Chislett, W.-K., \& Calder, R. (2018). The State of Self Care in Australia. BMC Complementary and Alternative Medicine,

6, 1-50. https://doi.org/10.1016/j.eujim.2014.03.00 8

Duhigg, C. (2012). The Habits of Individuals The Habits of Successful Organizations The Habits of Societies.

Elo, S., Kääriäinen, M., Kanste, O., Pölkki, T., Utriainen, K., \& Kyngäs, H. (2014). Qualitative Content Analysis: A Focus on Trustworthiness. SAGE Open, 1-10. https://doi.org/10.1177/215824401452263 3

Eller, L. S., Lev, E. L., Yuan, C., \& Watkins, A. V. (2018). Describing Self-Care Self-Efficacy: Definition, Measurement, Outcomes, and Implications. International Journal of Nursing Knowledge, 29(1), 38-48. https://doi.org/10.1111/20473095.12143

Fiebig, J. H., Gould, E. R., Ming, S., \& Watson, R. A. (2020). An Invitation to Act on the Value of Self-Care: Being a Whole Person in All That You Do. Behavior Analysis in Practice, 13(3), 559-567. https://doi.org/10.1007/s40617020-00442-x

Fishman, M. D. C. (2020). The Silver Linings Journal: Gratitude During a Pandemic. Journal of Radiology Nursing, 39(3), 149-150. https://doi.org/10.1016/j.jradnu.2020.05.0 05

Fredrickson, B. L. (2001). The role of positive emotions in positive psychology. The broaden-and-build theory of positive emotions. The American Psychologist, 56(3), 218-226.

http://www.ncbi.nlm.nih.gov/pubmed/113 15248

Garland, E. L., Farb, N. A., Goldin, P., \& Fredrickson, B. L. (2015). Mindfulness Broadens Awareness and Builds Eudaimonic Meaning: A Process Model of Mindful Positive Emotion Regulation. Psychological Inquiry, 26(4), 293-314.

https://doi.org/10.1080/1047840X.2015.10 64294

Gbhardt Taylor, S., \& Renpenning, K. (2011). Self-care science, nursing theory, and evidence-based practice. New York, New York, USA: Springer International Publishing. https://doi.org/10.5860/choice.49-2104

Godfrey, C. M., Harrison, M. B., Lysaght, R., Lamb, M., Graham, I. D., \& Oakley, P. (2011). Care of self - care by other - care of other: The

IHTP, 1(2), 161-175, 2021 CC BY-NC-ND 4.0

ISSN 2563-9269 
meaning of self-care from research, practice, policy and industry perspectives. International Journal of Evidence-Based Healthcare, 9(1), 3-24. https://doi.org/10.1111/j.17441609.2010.00196.x

Görlich, A. (2016). Poetic inquiry: understanding youth on the margins of education. International Journal of Qualitative Studies in Education, 29(4), 520-535. https://doi.org/10.1080/09518398.2015.10 63734

Guba, E. G., \& Lincoln, Y. S. (1994). Competing paradigms in qualitative research. In N. K. Denzin \& Y. S. Lincoln (Eds.), Handbook of qualitative research (pp. 105-117). Sage Publications, Inc.

Henning, M., Fox, G. R., Kaplan, J., Damasio, H., \& Damasio, A. (2017). A Potential Role for muOpioids in Mediating the Positive Effects of Gratitude. Frontiers in Psychology, 8(JUN), 868. https://doi.org/10.3389/fpsyg.2017.00868

Horesh, D., \& Brown, A. D. (2020). Covid-19 response: Traumatic stress in the age of Covid-19: A call to close critical gaps and adapt to new realities. Psychological Trauma: Theory, Research, Practice, and Policy, 12(4), 331335. https://doi.org/10.1037/TRA0000592

Jandrić, P. (2020). Postdigital Research in the Time of Covid-19. Postdigital Science and Education, 2(2), 233-238. https://doi.org/10.1007/s42438-020-001138

Januchowski-Hartley, S. R., Sopinka, N., Merkle, B. G., Lux, C., Zivian, A., Goff, P., \& Oester, S. (2018). Poetry as a Creative Practice to Enhance Engagement and Learning in Conservation Science. BioScience, 68(11), 905-911.

https://doi.org/10.1093/biosci/biy105

Kashdan, T. B., Afram, A., Brown, K. W., Birnbeck, M., \& Drvoshanov, M. (2011). Curiosity enhances the role of mindfulness in reducing defensive responses to existential threat. Personality and Individual Differences, 50(8), 1227-1232. https://doi.org/10.1016/j.paid.2011.02.015

Kissack, M. (2018). The Problem with Self-Care That Hummingbird Life. The Hummingbird Life Blog. https://www.thathummingbirdlife.com/blo $\mathrm{g} /$ the-problem-with-self-care

Lea, J., Cadman, L., \& Philo, C. (2015). Changing the habits of a lifetime? Mindfulness meditation and habitual geographies. Cultural Geographies, 22(1), 49-65. https://doi.org/10.1177/147447401453651 9

Lemon, N. (2021). Wellbeing in Initial Teacher Education: Using Poetic Representation to Examine Pre-Service Teachers Understanding of their Self-care Needs. Cultural Studies of Science Education, 2021(2),1-20. https://doi.org/10.1007/s11422-021-10034$y$

Lemon, N., \& McDonough, S. (2021). If not now, then when? Wellbeing and wholeheartedness in education. Educational Forum, 85(4), 1-20.

Lincoln, S. Y., Guba, E. G. (1985). Naturalistic inquiry. Sage.

Lomas, T., Heffferon, K., \& Ivatzan, I. (2014). Applied Positive Psychology: Integrated Positive Practice. London: Sage Publications Inc.

Louis, M. C., \& Lopez, S. J. (2014). Strengths interventions: Current progress and future directions. In A. Parks \& S. Schueller (Eds.), The Wiley Blackwell Handbook of Positive Psychological Interventions (pp. 66-89). Wiley-Blackwell.

Ludman, E. J., Peterson, D., Katon, W. J., Lin, E. H. B., Von Korff, M., Ciechanowski, P., Young, B., \& Gensichen, J. (2013). Improving confidence for self-care in patients with depression and chronic illnesses. Behavioral Medicine, 39(1), 1-6. https://doi.org/10.1080/08964289.2012.70 8682

Lyubomirsky, S. (2010). The how of happiness: a practical guide to getting the life you want. London: Piatkus.

Magyar-Moe, J. L. (2014). Applications of Positive Psychology to Individual Therapy. In The Wiley Blackwell Handbook of Positive Psychological Interventions (pp. 255-272). John Wiley \& Sons, Ltd. https://doi.org/10.1002/9781118315927.ch 14

Marks, N. A., Cordon, C., Aked, J., \& Thompson, S. (2008). Five ways to wellbeing. New economics foundation, 1-23. 
Matarese, M., Lommi, M., De Marinis, M. G., \& Riegel, B. (2018). A Systematic Review and Integration of Concept Analyses of Self-Care and Related Concepts. Journal of Nursing Scholarship, 50(3), 296-305. https://doi.org/10.1111/jnu.12385

McDonough, S. L. (2018). Inside the mentors' experience: Using poetic representation to examine the tensions of mentoring preservice teachers. Australian Journal of Teacher Education, 43(10), 98-115. https://doi.org/10.14221/ajte.2017v43n10. 6

McGarrigle, T., \& Walsh, C. A. (2011). Mindfulness, Self-Care, and Wellness in Social Work: Effects of Contemplative Training. Journal of Religion \& Spirituality in Social Work: Social Thought, 30(3), 212-233. https://doi.org/10.1080/15426432.2011.58 7384

McQuaid, M., \& Kern, P. (2017). Your wellbeing blueprint: feeling good and doing well at work. Melbourne, Australia: Michelle McQuaid Pty Ltd.

Narasimhan, M., Allotey, P., \& Hardon, A. (2019). Selfcare interventions to advance health and wellbeing: A conceptual framework to inform normative guidance. BMJ (Online), 365, 1-4. https://doi.org/10.1136/bmj.1688

Narasimhan, M., \& Kapila, M. (2019). Implications of self-care for health service provision. In Bulletin of the World Health Organization (Vol. 97, Issue 2, pp. 76-77). World Health Organization. https://doi.org/10.2471/BLT.18.228890

Neff, K. D. (2003). The Development and Validation of a Scale to Measure Self-Compassion. Self and Identity, 2(3), 223-250. https://doi.org/10.1080/15298860309027

Neff, K. D., \& McGehee, P. (2010). Self-compassion and psychological resilience among adolescents and young adults. Self and Identity, 9(3), 225-240. https://doi.org/10.1080/152988609029793 07

Neff, K., \& Germer, C. (2018). The Mindful SelfCompassion Workbook: A Proven Way to Accept Yourself, Build Inner Strength, and Thrive. Guilford Press. https://www.guilford.com/books/The-
Mindful-Self-Compassion-Workbook/NeffGermer/9781462526789

Parker, C., Scott, S., \& Gedded, A. (2019). Snowball Sampling. SAGE Research Methods Foundations; SAGE Publications Ltd. https://doi.org/10.4135/978152642103683 1710

Parulekar, M., \& Mekoth, N. (2017). Insights into selfmedication. International Journal of Pharmaceutical Sciences and Business Management., $\quad$ 5(2), 1-15. http://irgu.unigoa.ac.in/drs/handle/unigoa/ 4704

Polit, D. F., \& Beck, C. T. (2012). Nursing research: Principles and methods. Lippincott Williams \& Wilkins

Prendergast, M. (2009). "Poem is What?" Poetic Inquiry in Qualitative Social Science Research. International Review of Qualitative Research, 1(4), 541-568. https://doi.org/10.1525/irqr.2009.1.4.541

Richardson, L. (1997). Fields of Play: Constructing an Academic Life. New Brunswick, New Jersey: Rutgers University Press.

Riegel, B., Barbaranelli, C., Sethares, K. A., Daus, M., Moser, D. K., Miller, J. L., Haedtke, C. A., Feinberg, J. L., Lee, S., Stromberg, A., \& Jaarsma, T. (2018). Development and initial testing of the self-care of chronic illness inventory. Journal of Advanced Nursing, 74(10), 2465-2476. https://doi.org/10.1111/jan.13775

Riegel, B., Dunbar, S. B., Fitzsimons, D., Freedland, K. E., Lee, C. S., Middleton, S., Stromberg, A., Vellone, E., Webber, D. E., \& Jaarsma, T. (2019). Self-care research: Where are we now? Where are we going? International Journal of Nursing Studies. https://doi.org/10.1016/j.ijnurstu.2019.103 402

Riegel, B., Jaarsma, T., \& Strömberg, A. (2012). A Middle-Range Theory of Self-Care of Chronic Illness. Advances in Nursing Science, 35(3), 194-204. https://doi.org/10.1097/ANS.0b013e31826 1 b1ba

Roche, L. (2020). Finding A Doorway into Bliss. https://www.irest.org/blog/nondualism/finding-doorway-bliss-lorin-rochediscovering-meditation-his-life-s-work-and 
Seligman, M. E. P. (2011). Flourish. Melbourne: Random House Australia.

Shapiro, S. L., \& Carlson, L. E. (2017). The Art and Science of Mindfulness: Integrating Mindfulness into Psychology and the Helping Professions. In S. L. Shapiro \& L. E. Carlson (Eds.), The art and science of mindfulness: Integrating mindfulness into psychology and the helping professions (pp. 115-126). American Psychological Association.

Shapiro, S. L., Carlson, L. E., Astin, J. A., \& Freedman, B. (2006). Mechanisms of mindfulness. Journal of Clinical Psychology, 62(3), 373386. https://doi.org/10.1002/jclp.20237

The Global Happiness Council. (2018). Global Happiness Policy Synthesis 2018. 1-264. https://www.researchgate.net/publication/ 323152606

Valizadeh-Haghi, S., Khazaal, Y., \& Rahmatizadeh, S. (2021). Health websites on COVID-19: Are they readable and credible enough to help public self-care? Journal of the Medical Library Association, 109(1), 75-83. https://doi.org/10.5195/jmla.2021.1020

Vanwesemael, T., Boussery, K., Manias, E., Petrovic, M., Fraeyman, J., \& Dilles, T. (2018). Self- management of medication during hospitalisation: Healthcare providers' and patients' perspectives. Journal of Clinical Nursing, 27(3-4), 753-768. https://doi.org/10.1111/jocn.14084

Waters, L., Algoe, S. B., Dutton, J., Emmons, R., Fredrickson, B. L., Heaphy, E., Moskowitz, J. T., Neff, K., Niemiec, R., Pury, C., \& Steger, M. (2021). Positive psychology in a pandemic: buffering, bolstering, and building mental health. The Journal of Positive Psychology, 1-21.

https://doi.org/10.1080/17439760.2021.18 71945

Watkins, P. C. (2014). Gratitude and the good life: Toward a psychology of appreciation. In Gratitude and the Good Life: Toward a Psychology of Appreciation. Springer Netherlands. https://doi.org/10.1007/97894-007-7253-3

World Health Organisation. (2013). Self-care for health: A handbook for community health workers \& volunteers. In WHO. World Health Organization, Regional Office for South-East Asia. 


\section{FIGURE 1: Dimensions of Self-Care}

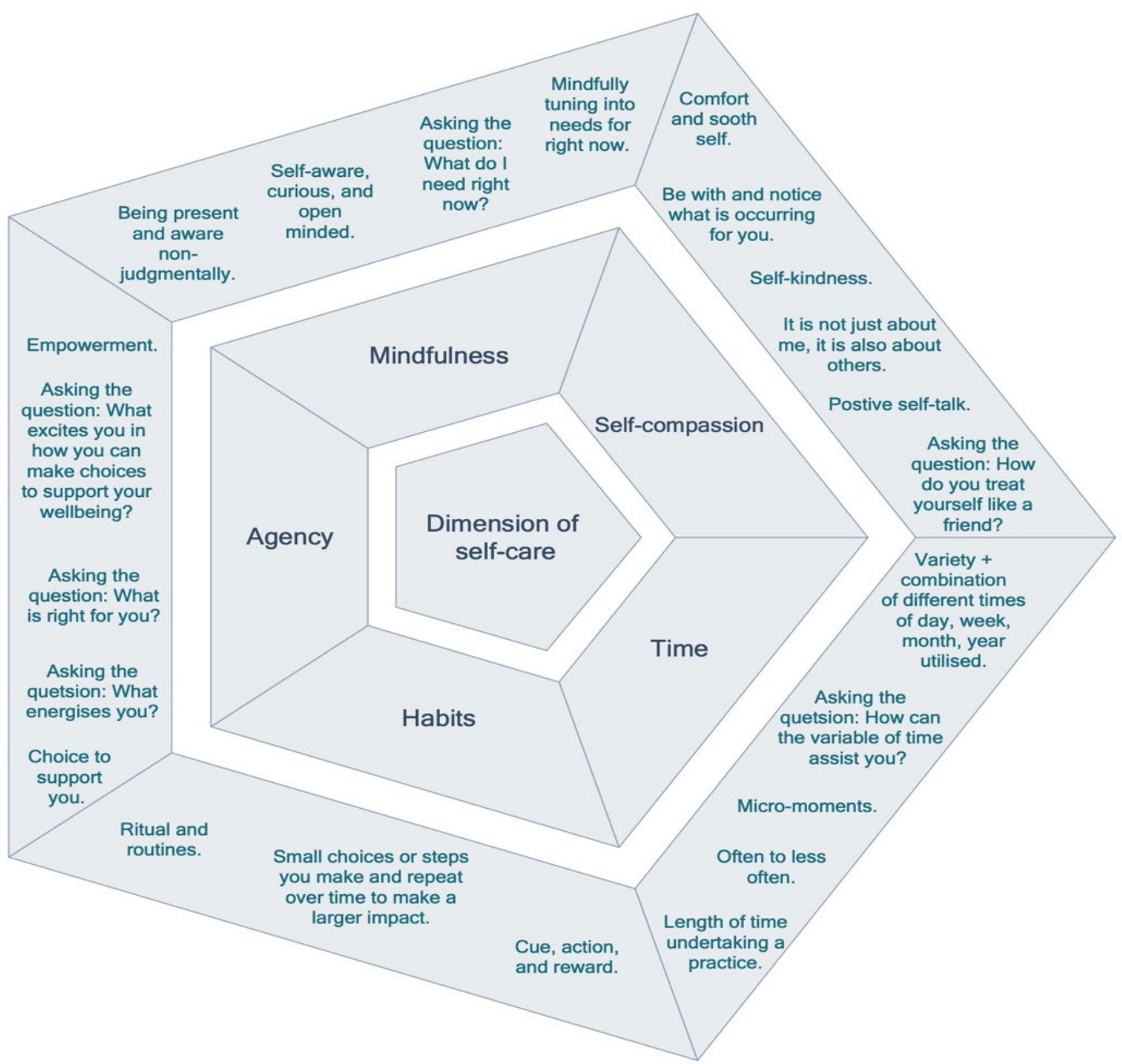

